\title{
Age-related changes in bile acid synthesis and hepatic nuclear receptor expression
}

\author{
M. Bertolotti", C. Gabbi*, C. Anzivino*, M. Crestani ${ }^{\dagger}$, N. Mitro ${ }^{\dagger}$, M. Del Puppo ${ }^{\ddagger}$, C. Godio $^{\dagger}$, \\ E. De Fabiani ${ }^{\dagger}$, D. Macchioni*, L. Carulli", A. Rossi", M. Ricchi*, P. Loria* and N. Carulli* \\ ${ }^{\star}$ University of Modena and Reggio Emilia, Modena, Italy, ${ }^{\dagger}$ University of Milan, Milan, Italy, ${ }^{\ddagger}$ University of Milano Bicocca, \\ Monza, Italy
}

Abstract

Department of Medicine, Endocrinology, Metabolism and Geriatrics, University of Modena and Reggio Emilia, Modena, Italy (M. Bertolotti, C. Gabbi, C. Anzivino, D. Macchioni, L. Carulli, M. Ricchi, P. Loria, N. Carulli); Department of Pharmacological Sciences, University of Milan, Milan, Italy (M. Crestani, N. Mitro, C. Godio, E. De Fabiani); Department of Experimental and Environmental Medicine and Biotechnology, University of Milano Bicocca, Monza, Italy (M. Del Puppo); Department of Surgical Sciences, University of Modena and Reggio Emilia, Modena, Italy (A. Rossi).

Correspondence to: Marco Bertolotti, MD, Dipartimento di Medicina, Endocrinologia, Metabolismo e Geriatria, Nuovo Ospedale Civile, via Giardini 1355, 41040 Modena, Italy.

Tel.: +39059 3961802; fax: +39059 3961335;

e-mail: bertolotti.marco@unimore.it

Received 6 December 2006; accepted 13 February 2007

\section{Introduction}

Hepatic degradation to bile acids is the most relevant metabolic pathway whereby the organism can dispose of excess cholesterol [1,2]. Bile acids are known to exert feedback inhibition on this process and on the activity of the limiting enzyme of the main biosynthetic pathway, cholesterol $7 \alpha$-hydroxylase (CYP7A1) [1-3].

Recent evidence highlighted the role of nuclear receptors in the transcriptional control of CYP7A1 [4-6] suggesting a cascade mechanism of control where the interaction of hydrophobic bile acids with farnesoid X receptor (FXR), now identified as the bile acid receptor, triggers overexpression of the co-repressor short heterodimer partner (SHP) leading in turn to down-regulation of CYP7A1 gene 
transcription $[7,8]$. This mechanism involves a negative interaction with the co-activator CYP7A1 promoter binding factor/liver receptor homologue-1 (CPF/LRH-1). Another nuclear receptor, hepatocyte nuclear factor 4 (HNF-4), was shown to exert an important stimulation of CYP7A1 transcription, in part independently of the FXR and SHPmediated cascade, via interaction with the transcriptional complex at the promoter level $[6,9]$.

These mechanisms of regulation have been defined mainly in cellular models; their role in humans is still largely unknown. The feedback mechanism is certainly operating in humans $[10,11]$; furthermore, manipulations affecting bile acid synthesis and CYP7A1 activity lead to significant changes in plasma low-density lipoprotein (LDL) levels, due to corresponding changes in the expression and function of the hepatic LDL receptor, as shown with the bile acid-sequestering agent cholestyramine $[11,12]$. Therefore, insight in the regulation of this pathway bears important implications such as the definition of molecular targets for the management of hypercholesterolaemia.

The effects of ageing on cholesterol metabolism and on bile acid synthesis have been characterized in the past. Epidemiological studies have shown that plasma cholesterol levels and the prevalence of cholesterol gallstone disease increase with advancing age [13-15]. Increased biliary secretion of cholesterol might account for the latter phenomenon [16]; reduction in bile acid synthesis $[16,17]$ could also play a causal role.

The aims of the present study were to characterize the role of hepatic nuclear receptors on bile acid synthesis and on the expression of CYP7A1 in the human liver, and to investigate the alterations associated with ageing as related with changes in circulating hormone levels in patients not receiving any treatment with agents affecting bile acid metabolism.

\section{Materials and methods}

\section{Patients}

Twenty-three consecutive patients ( 11 males, 12 females, age range $18-81$ years) referred to the Policlinico Hospital in Modena for operation were studied. Thirteen of them had stabilized cholesterol gallstone disease; ten of them required abdominal operation because of colon cancer, pancreatic cancer, gastric cancer or liver donation. According to our protocol, patients with initial gastrointestinal cancer could be included in the study provided that liver samples were free from neoplastic disease.

None of the subjects had alterations in liver and gastrointestinal function, or major metabolic diseases. None of them was taking bile acids, cholestyramine or other agents known to affect cholesterol metabolism. Most of the patients (9 gallstone and 7 control subjects) were already reported in a preliminary study aimed to investigate the effects of cholelithiasis on hepatic nuclear receptor expression [18].

The patients gave their informed consent to the protocol of the study, which was approved by the local Ethical Committee.
During operation, in the morning after an overnight fast, a liver biopsy (30-150 mg) was taken, immediately frozen in liquid nitrogen and stored at $-80{ }^{\circ} \mathrm{C}$ until analysed. Histology did not show alterations related to acute or chronic liver disease; steatosis was either absent or minimal (less than $20 \%$ ).

Fasting blood samples were taken for determination of serum lipids, hormone levels and $7 \alpha$-hydroxy-4-cholesten3-one concentrations.

\section{Quantification of hepatic mRNA levels by real-time RT-PCR}

After standard extraction, total RNA was reverse-transcribed with the Superscript First-Strand Synthesis System (Invitrogen, Milano, Italy). PCR analysis was performed as described [18,19], using the IQ Sybr Green Method (BioRad, Milano, Italy), in order to detect mRNA expression levels of CYP7A1 and of the main nuclear receptors involved in its transcriptional regulation, FXR, SHP, CPF/ LRH-1, and HNF-4. 18S rRNA was used as housekeeping gene.

Results are shown as expression abundance relative to $18 \mathrm{~S}$.

\section{Determination of serum $7 \alpha$-hydroxy-4-cholesten-3- one, lipid and hormone levels}

Serum levels of $7 \alpha$-hydroxy-4-cholesten-3-one were determined by gas-liquid chromatography: mass spectrometry (GC-MS) assay as described [18], using 19-hydroxycholesterol as internal standard. After extraction, purification and derivatization, aliquots of the silylated mixtures were injected in a Thermofinnigan GC-Q equipment for analysis [18]

Serum concentrations of total cholesterol, high-density lipoprotein (HDL) cholesterol, LDL cholesterol and triglycerides were determined by enzymatic-colorimetric technique (Boehringer, Mannheim, Germany) on an automated equipment (Modular, Roche, Mannheim, Germany); apo AI and apo B were analysed by standard immunochemicalnephelometric analysis on a BNII instrument (Dade Behring, Eschborn, Germany).

Basal serum levels of insulin, C-peptide, thyrotropin (TSH), free triiodothyronine $\left(\mathrm{F}-\mathrm{T}_{3}\right)$ and free thyroxine $\left(\mathrm{F}-\mathrm{T}_{4}\right)$ were determined by chemiluminescence on an Advia Centaur equipment (Bayer Italia, Milano, Italy); growth hormone (GH) and insulin-like growth factor-I (IGF-I) were determined by chemiluminescence on a Liaison equipment (DiaSorin, Saluggia, Italy).

\section{Statistical analysis}

Linear correlation analysis and, when appropriate, multiple stepwise regression analysis were performed by the least square method. Analysis with relative mRNA tissue contents was conducted after log transformation in order to better approximate normal distribution. 


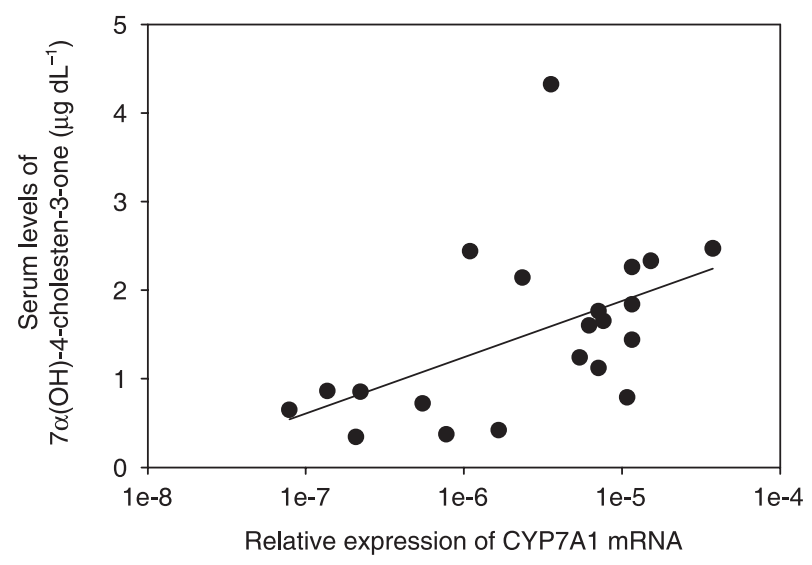

Figure 1 Correlation between hepatic gene expression of CYP7A1 and serum levels of $7 \alpha$-hydroxy-4-cholesten-3-one as a marker of bile acid synthesis rate and of CYP7A1 activity in the population investigated $(n=21)$. The relative mRNA abundance of CYP7A1 was assayed by quantitative real-time RT-PCR and expressed as relative to $18 \mathrm{~S}$ as housekeeping gene. Serum concentrations of $7 \alpha$-hydroxy-4-cholesten-3-one were assayed by GC-MS.

Linear regression analysis was performed by the least square method after log transformation of CYP7A1 mRNA levels. $r=0.50, P<0.05$.

Significance was accepted at the $P<0.05$ level. Statistical analysis was performed with the aid of SPSS statistical software (version 13.0 for Windows) on a PC workstation.

\section{Results}

As illustrated in Fig. 1, a significant correlation $(r=0 \cdot 50$, $P<0.05)$ is present between hepatic expression of CYP7A1 and serum concentrations of $7 \alpha$-hydroxy-4-cholesten-3one, a precursor of primary bile acids recognized as a marker of bile acid synthesis rate and of CYP7A1 activity [20]. These data confirm that circulating levels of $7 \alpha-$ hydroxy-4-cholesten-3-one mirror to some extent hepatic expression, and presumably activity, of CYP7A1 even in the absence of treatment with agents affecting bile acid and lipid metabolism.

Figure 2 shows the correlation between tissue expression of CYP7A1 and the nuclear receptors/co-regulators investigated, expressed on a log scale. Simple regression analysis showed a significant direct correlation with tissue expression of HNF-4 and CPF/LRH-1, and a non-significant correlation trend with SHP. A similar non-significant trend was also observed with FXR $(r=0 \cdot 38, P=$ n.s., data not illustrated).When performing stepwise linear regression analysis with CYP7A1 expression as the dependent variable, the highest degree of correlation was detected with HNF-4 expression $(r=0.55, P<0.05)$, all other genes bringing non-significant contribution. Tissue expression of HNF-4 was also highly correlated with that of CPF/LRH-1 ( $r=0.65, P<0 \cdot 05)$; furthermore, HNF-4 mRNA levels were significantly correlated with serum concentrations of
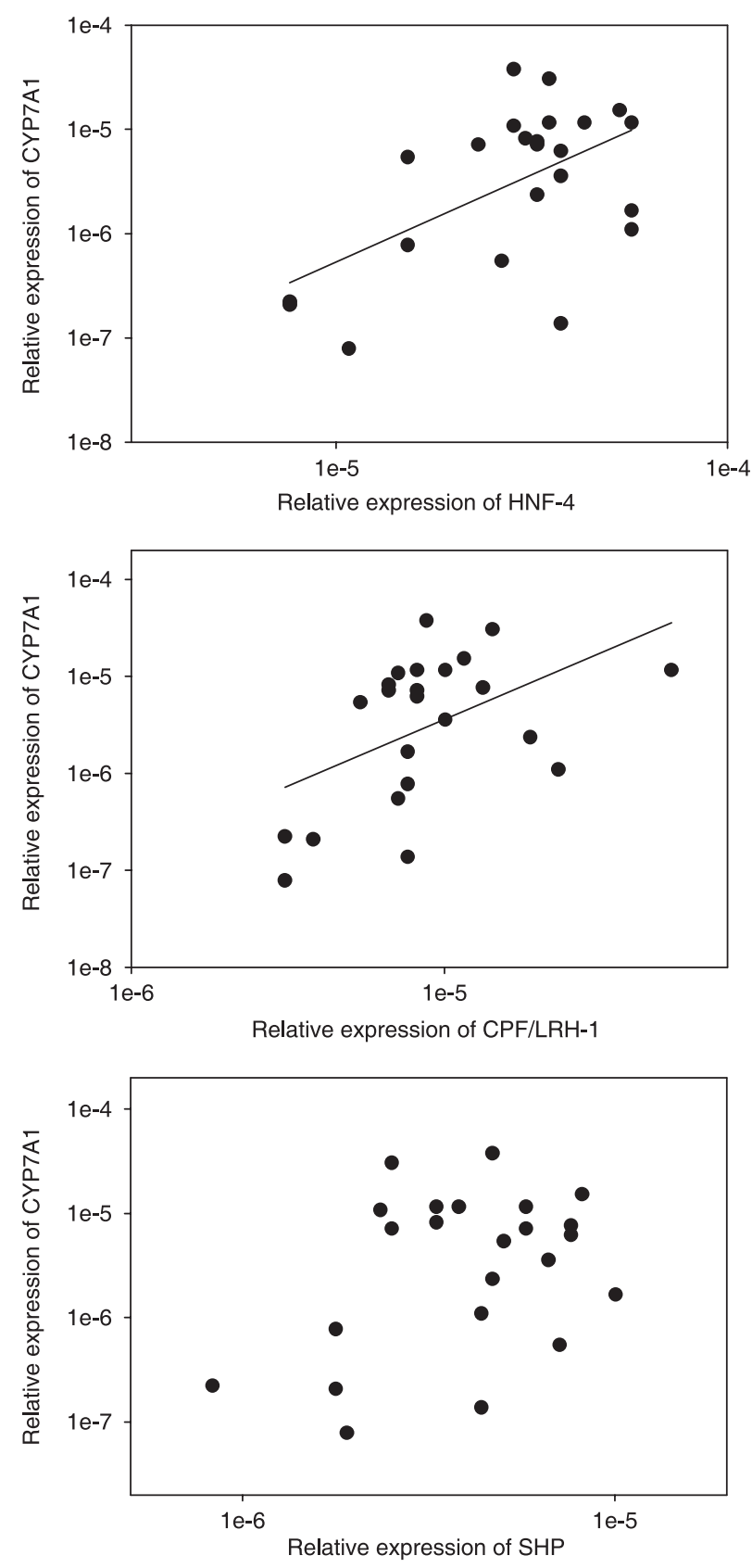

Figure 2 Correlation between tissue gene expression levels of CYP7A1 (as the dependent variable) and, from top to bottom, HNF-4, CPF/LRH-1 and SHP in the patients investigated $(n=23)$. The relative mRNA abundance of the individual genes was assayed by quantitative real-time RT-PCR and expressed as relative to $18 \mathrm{~S}$ as housekeeping gene. Linear regression analysis was performed by the least square method after log transformation. HNF-4 vs. CYP7A1: $r=0 \cdot 55, P<0 \cdot 05 . \mathrm{CPF} / \mathrm{LRH}-1$ vs. CYP7A1: $r=0.48, P<0.05$. SHP vs. CYP7A1: $r=0.38, P=$ n.s.

$7 \alpha$-hydroxy-4-cholesten-3-one $(r=0.47, P<0.05)$ (data not illustrated).

No difference in tissue expression of any of the genes investigated was detected in subjects with cholesterol 

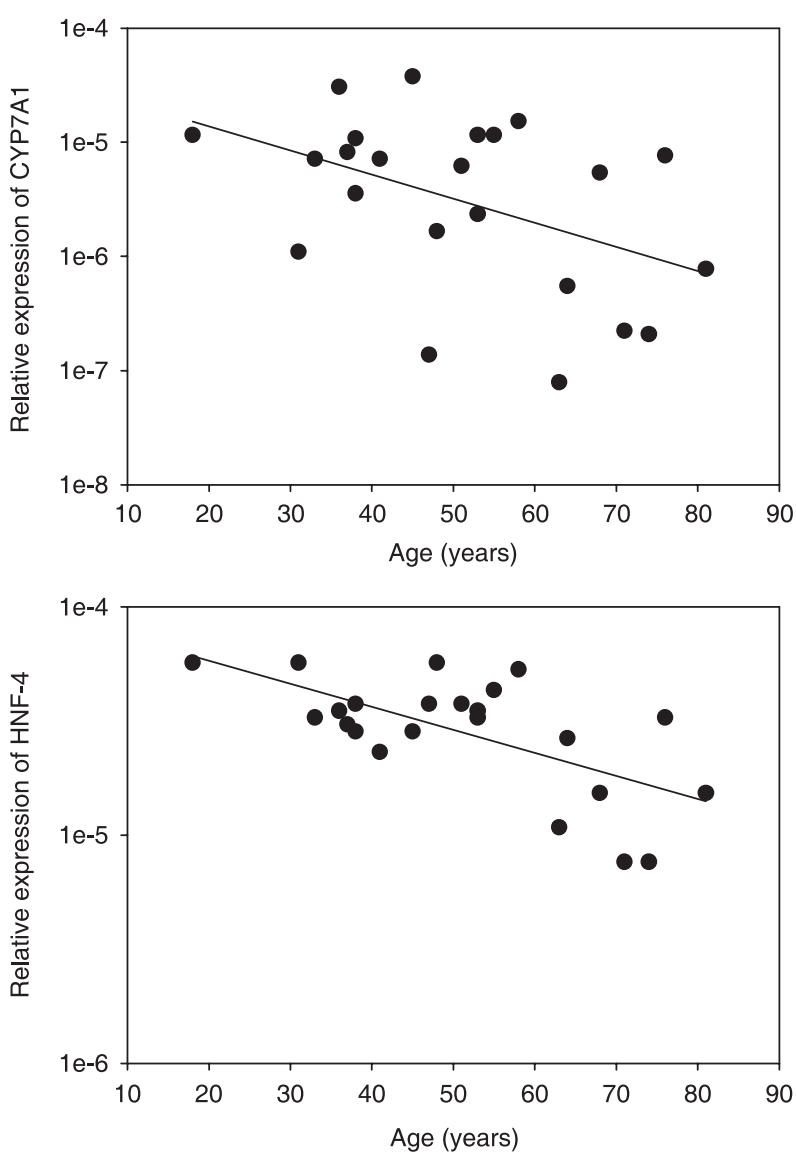

Figure 3 Correlation between age and tissue expression of CYP7A1 (upper panel, $n=23$ ) and tissue expression of HNF-4 (lower panel, $n=23$ ). The relative mRNA abundance of CYP7A1 and HNF-4 was assayed by quantitative real-time RT-PCR and expressed as relative to $18 \mathrm{~S}$ as housekeeping gene. Linear regression analysis was performed by the least square method after $\log$ transformation of CYP7A1 and HNF-4 mRNA levels. Age vs. CYP7A1: $r=-0 \cdot 45, P<0 \cdot 05$. Age vs. HNF-4: $r=-0 \cdot 64$, $P<0 \cdot 05$.

gallstone disease versus those without gallstones, in agreement with a preliminary report of this group [18] (data not shown).

As shown in Fig. 3, a significant inverse correlation was detected between age and tissue CYP7A1 expression. A significant correlation was also observed between age and serum $7 \alpha$-hydroxy-4-cholesten-3-one $(r=-0 \cdot 44, P<0 \cdot 05$, data not illustrated). In particular, a close inverse correlation was detected between age and hepatic expression of HNF-4 $(r=-0.64, P<0.05)$. No correlation was present with the other nuclear receptors investigated (data not shown).

Table 1 shows the lipid parameters and the hormones analysed in the study.

A significant inverse correlation was detected between age and plasma $\mathrm{F}_{-} \mathrm{T}_{3}(r=-0.57, P<0.05$, data not illustrated) and between age and IGF-I (Fig. 4). Circulating levels of other hormones investigated (insulin, C-peptide, TSH,

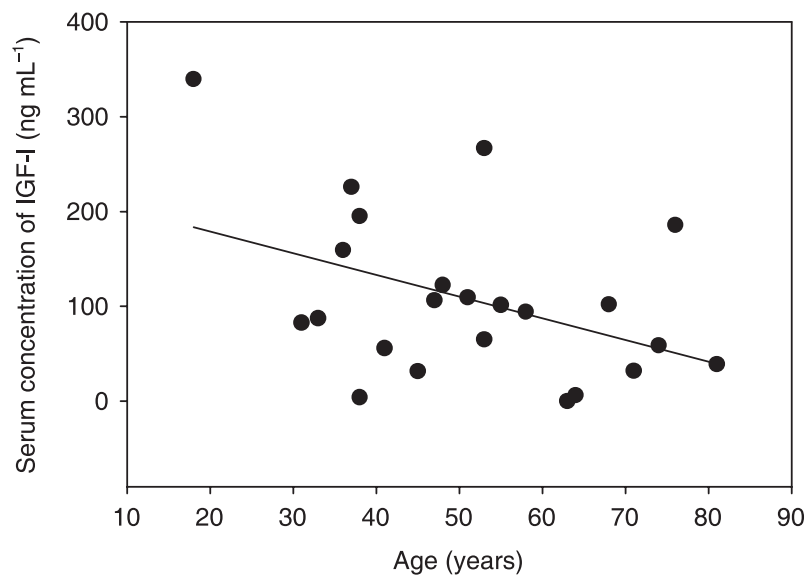

Figure 4 Correlation between age and serum levels of IGF-I in the population investigated $(n=23)$. Serum hormone levels were analysed by chemiluminescence analysis. Linear regression analysis was performed by the least square method. Age vs. IGF-I: $r=-0 \cdot 43, P<0 \cdot 05$.

$\mathrm{F}_{-} \mathrm{T}_{4}, \mathrm{GH}$ ) were not significantly correlated with age (data not shown).

Whereas serum $\mathrm{F}_{-} \mathrm{T}_{3}$ did not show a significant correlation with any of the parameters investigated (data not shown), serum concentrations of IGF-I were directly correlated with serum $7 \alpha$-hydroxy-4-cholesten-3-one, with tissue expression of CYP7A1 and of HNF-4 as illustrated in Fig. 5.

No correlation was observed between age and any of the investigated parameters of lipid profile (serum total cholesterol, HDL cholesterol, LDL cholesterol, triglycerides, apo $\mathrm{AI}$, apo B) in the present patient group; likewise, no correlation was present between any of these parameters and gene expression levels of CYP7A1 and of the other nuclear receptors analysed (data not shown).

\section{Discussion}

A body of experimental data has recently brought new insights into the molecular mechanisms of regulation of bile acid synthesis [5,6,9]; nonetheless direct evidence in humans, in particular concerning the regulation of CYP7A1 expression, is scarce.

Previous findings by Rudling et al. [21] have shown specular changes in hepatic mRNA abundance of CYP7A1 after treatment with cholestyramine and chenodeoxycholic acid; such changes were also correlated with tissue abundance of LDL receptor.

A recent report by Abrahamsson et al. suggested that changes in CYP7A1 mRNA after resin treatment might be mediated by alterations in hepatic expression of HNF-4 [22]. Our evidence, obtained in a population of untreated subjects, is in agreement with these data.

The present results show a strict correlation between hepatic CYP7A1 abundance and HNF-4 mRNA levels. At multiple regression analysis, $\mathrm{HNF}-4$ expression was the 

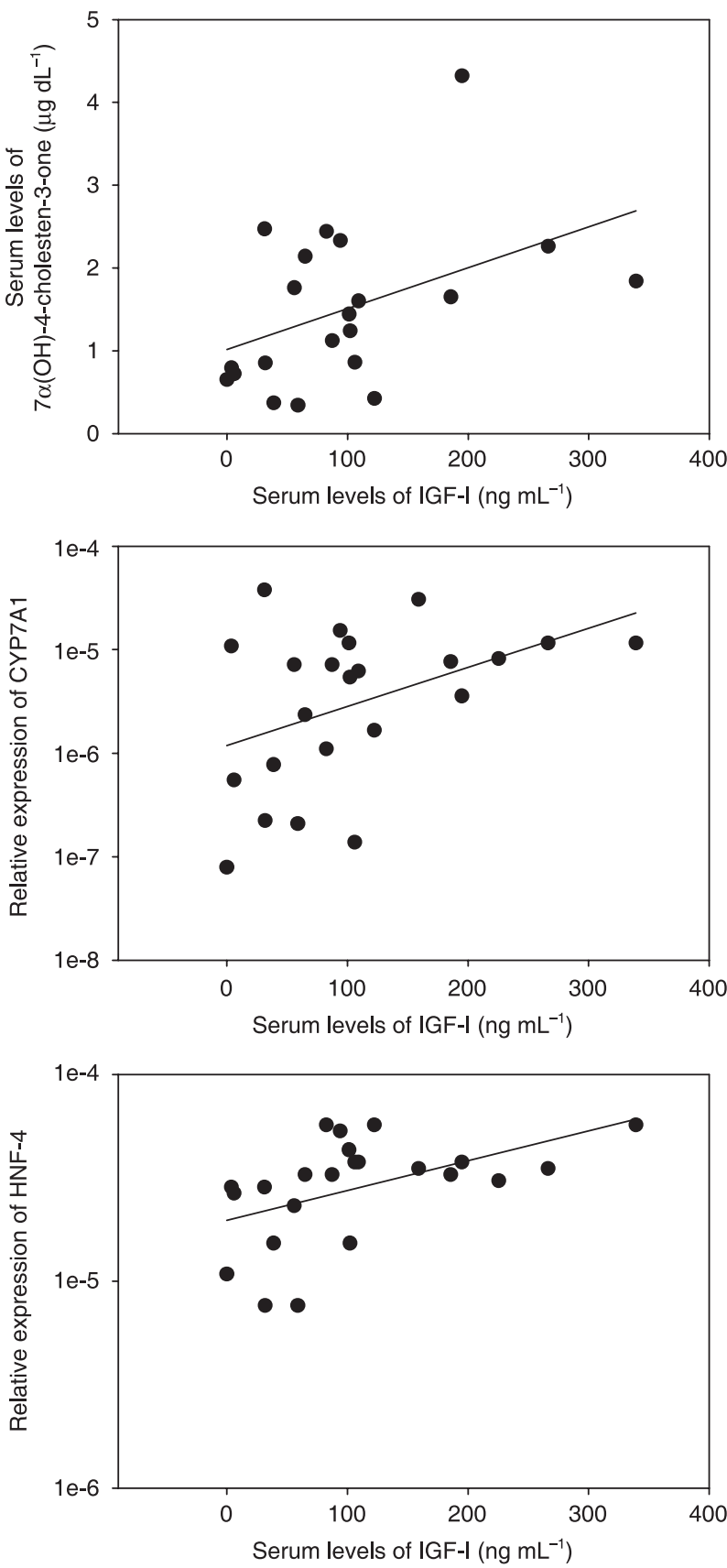

Figure 5 Correlation between serum levels of IGF-I and serum concentrations of $7 \alpha$-hydroxy-4-cholesten-3-one (upper panel, $n=21$ ), tissue expression of CYP7A1 (middle panel, $n=23$ ) and tissue expression of HNF-4 (lower panel, $n=23$ ). Serum IGF-I levels were analysed by chemiluminescence analysis. Serum concentrations of $7 \alpha$-hydroxy-4-cholesten-3-one were assayed by GC-MS. The relative mRNA abundance of CYP7A1 and HNF-4 was assayed by quantitative real-time RT-PCR and expressed as relative to $18 \mathrm{~S}$ as housekeeping gene. Linear regression analysis was performed by the least square method after log transformation of CYP7A1 and HNF-4 mRNA levels. IGF-I vs. $7 \alpha$-hydroxy-4cholesten-3-one: $r=0 \cdot 44, P<0 \cdot 05$.IGF-I vs. CYP7A1: $r=0.43$, $P<0.05$. IGF-I vs. HNF-4: $r=0.49, P<0.05$. 
closest predictor of CYP7A1 expression, all other genes bringing non-significant contribution to the regression profile. Of course, the mere presence of a correlation does not imply a cause and effect relationship between the parameters investigated, but the present data are highly suggestive for a modulating effect of $\mathrm{HNF}-4$ on bile acid synthesis. This view is further supported by the data on circulating $7 \alpha$-hydroxy-4-cholesten-3-one, whose levels correlate with tissue expression of $\mathrm{HNF}-4$.

Serum levels of this precursor of bile acid synthesis correlate with tissue expression of CYP7A1 (see Fig. 1). Whereas the correspondence between serum $7 \alpha$-hydroxy4-cholesten-3-one concentrations and hepatic CYP7A1 activity is well characterized [20], as far as we know this is the first report which directly addresses the relationship with hepatic CYP7A1 expression.

Evidence in patients with cerebrotendineous xanthomatosis is also indirectly consistent with a role of HNF-4 as a transcriptional activator of CYP7A1 [23]. Finally, a body of evidence has supported a relevant role of $\mathrm{HNF}-4$ as an activator of CYP7A1 transcription in nonhuman models [24-26].

Experiments are currently underway to determine hepatic protein levels of CYP7A1 and HNF-4 as related to gene expression profile in untreated and treated conditions.

Hepatic abundance of CPF/LRH-1 also correlates with CYP7A1 and with HNF-4 expression. With the limitations previously mentioned, our findings are consistent with a reciprocal interaction of these two transcriptional activators, suggested by previous findings [27].

Surprisingly, no negative correlation between SHP and CYP7A1 was detected; a positive trend was instead disclosed. This is against the leading hypothesis of a regulatory cascade with a crucial role of SHP in down-regulating CYP7A1 transcription $[7,8]$.

It is likely that in man, at least in basal conditions, SHPmediated suppression is not the predominant mechanism of regulation of bile acid synthesis. We cannot rule out that in different clinical settings changes in SHP expression may take place and bring a more substantial regulatory contribution; nonetheless it is interesting to recall that even in the previously mentioned paper by Abrahamsson et al. [22] no changes in SHP expression were shown with either chenodeoxycholic acid or cholestyramine treatment. Obviously, our findings do not rule out the possibility of a regulatory role of SHP on CYP7A1 transcription, independently of measurable changes in its expression levels, in the presence of other coactivators. At any rate, these findings underline the difficulty to extrapolate data obtained in cultured cells and in experimental animals to the complexity of human physiology.

The role of SHP-independent mechanisms in the regulation of bile acid synthesis and of CYP7A1 transcription has been underlined $[28,29]$, highlighting the role of pathways involving cytokine expression and intracellular kinase pathways [30,31] and showing that bile acids impair the transcriptional machinery by determining the dissociation of transcriptional coactivators from the CYP7A1 promoter [19].
We obviously cannot rule out a relevant role for other nuclear receptors/co-activators or enzymes that were not investigated in the present study; preliminary data from this laboratory ([18] and Bertolotti et al. unpublished observations) failed to show, at any rate, any significant correlation between hepatic mRNA content of CYP7A1 and tissue expression of peroxysome proliferator-activated receptor (PPAR)- $\gamma$ coactivator-1 (PGC-1), a co-activator whose role in the molecular regulation of bile acid synthesis and CYP7A1 transcription has been underlined [9], nor with hepatic expression of phosphoenolpyruvate carboxykinase (PEPCK), an enzyme of gluconeogenesis whose regulation was shown to mirror that of CYP7A1 [19].

The data presented indicate that ageing inversely correlates with bile acid synthesis and hepatic CYP7A1 expression. Even if the literature in this regard is scarce, the present findings are consistent with previous evidence obtained in humans in vivo by this group [17] and by others [16].

Such reduced rate of bile acid synthesis may play a relevant role in a number of alterations of cholesterol metabolism, among which increased biliary cholesterol saturation and cholesterol gallstone disease prevalence, observed with advancing age.

We were not able to observe any changes in lipid and lipoprotein profile, either related to age or to hepatic gene expression of CYP7A1 and of the investigated nuclear receptors. We need to consider that serum cholesterol and triglyceride levels are influenced by many interacting factors and subtle spontaneous changes in bile acid synthesis and CYP7A1 expression may have failed to bear a significant impact in a relatively small patient population.

The causes of age-related reduction of bile acid synthesis and CYP7A1 expression remain to a large extent elusive; a reduction in whole body bile acid synthesis might theoretically be accounted for by a reduction in functioning liver mass, as suggested by studies on quantitative liver function [32]. The described decrease in CYP7A1 expression indeed points toward more subtle mechanisms of regulation, which might be related to the observed changes in the hormonal pattern.

Our data on the inverse correlation between ageing and IGF-I are consistent with previous epidemiological evidence [33] and suggest a causal relationship between IGF-I levels and bile acid synthesis/CYP7A1 expression, which might involve $\mathrm{HNF}-4$ as a critical regulator. In animal model experimental treatment with $\mathrm{GH}$ was shown to induce hepatic expression of $\mathrm{HNF}-4$ and other liver-enriched transcription factors as well [34-36]; on the other hand, members of the hepatocyte nuclear factor (HNF) family, a group of liverenriched transcription factors with relevant functions in liver differentiation and function [37] are capable of modulating the expression of IGF-I in isolated cell model $[38,39]$. It cannot therefore be excluded that hormones of the $\mathrm{GH} / \mathrm{IGF}$ axis and members of the HNF family can modulate each other in a feed-forward loop.

Whatever the intimate molecular pathways of regulation, quite a few pieces of evidence support the view that $\mathrm{GH}$ may exert a stimulatory action on bile acid synthesis. Data in hypophysectomized rats and mice have shown reduced 
serum levels of $7 \alpha$-hydroxy-4-cholesten-3-one and CYP7A1 activity, which could partly be reversed by GH treatment $[40,41]$. Data in humans are once again conflicting; previous evidence using faecal sterol analysis showed a stimulatory effect of $\mathrm{GH}$ treatment on bile acid production in $\mathrm{GH}$ deficient subjects [42], whereas more recent evidence failed to show an increase in serum $7 \alpha$-hydroxy-4-cholesten-3-one in comparable conditions [43]. We have no obvious explanation for these discrepancies; we might speculate that physiological age-related changes in IGF-I levels exert different metabolic effects compared with those induced by $\mathrm{GH}$ treatment. Furthermore, previous reports have suggested that the metabolic effects of $\mathrm{GH}$ and those of IGF-I may be relatively distinct, and independent on each other $[44,45]$.

In conclusion, the present findings support a regulatory role for $\mathrm{HNF}-4$, and possibly for CPF/LRH-1, on bile acid synthesis and hepatic CYP7A1 expression with no evidence for a suppressive role of SHP. The reduction of bile acid synthesis and CYP7A1 expression related with ageing is probably mediated by corresponding alterations in the GH/IGF axis and in HNF-4 expression. These data might help to clarify the pathogenesis of some of the changes in cholesterol metabolism observed with advancing age and, hopefully, to identify potential molecular targets for novel pharmacological approaches aimed to prevent the onset and complications of cholesterol accumulation conditions.

\section{Acknowledgements}

The Authors wish to thank Drs Enrica Baraldi and Walter Tizzanini (Dipartimento di Servizi Diagnostici, di Laboratorio e di Medicina Legale, Azienda Ospedaliera di Modena) for analysis of serum hormone levels and lipid profile.

This work was supported by 5 th Framework Programme grant QLGI-CT-2001-01513 and by COFIN-PRIN grants 2002062991 and 2004067491.

\section{References}

1 Princen HMG, Post SM, Twisk J. Regulation of bile acid biosynthesis. Curr Pharm Des 1997;3:59-84.

2 Vlahcevic ZR, Pandak WM, Stravitz RT. Regulation of bile acid biosynthesis. Gastroenterol Clin North Am 1999;28:1-25.

3 Russell DW. The enzymes, regulation, and genetics of bile acid synthesis. Annu Rev Biochem 2003;72:137-74.

4 Chawla A, Repa JJ, Evans RM, Mangelsdorf DJ. Nuclear receptors and lipid physiology: opening the $\mathrm{X}$-files. Science 2001;294:1866-70.

5 Goodwin B, Kliewer SA. Nuclear receptors. I. Nuclear receptors and bile acid homeostasis. Am $\mathcal{F}$ Physiol Gastrointest Liver Physiol 2002;282:G926-31.

6 Chiang JYL. Regulation of bile acid synthesis. pathways, nuclear receptors, and mechanisms. F Hepatol 2004;40:539-51.

7 Lu TT, Makishima M, Repa JJ, Schoonjans K, Kerr TA, Auwerx J et al. Molecular basis for feedback regulation of bile acid synthesis by nuclear receptors. Mol Cell 2000;6:507-15.
8 Goodwin B, Jones SA, Price RR, Watson MA, McKee DD, Moore LB et al. A regulatory cascade of the nuclear receptors FXR, SHP-1, and LRH-1 represses bile acid biosynthesis. Mol Cell 2000;6:517-26.

9 De Fabiani E, Mitro N, Godio C, Gilardi F, Caruso D, Crestani $M$. Bile acid signaling to the nucleus: finding new connections in the transcriptional regulation of metabolic pathways. Biochimie 2004;86:771-8.

10 Reihnér E, Björkhem I, Angelin B, Ewerth S, Einarsson K. Bile acid synthesis in humans: regulation of hepatic microsomal cholesterol $7 \alpha$-hydroxylase activity. Gastroenterology 1989;97:1498-505.

11 Bertolotti M, Abate N, Loria P, Dilengite M, Carubbi F, Pinetti A et al. Regulation of bile acid synthesis in humans: effect of treatment with bile acids, cholestyramine or simvastatin on cholesterol $7 \alpha$-hydroxylation rates in vivo. Hepatology 1991;14:830-7.

12 Bertolotti M, Zambianchi L, Carulli L, Simonini MS, Del Puppo M, Galli Kienle $M$ et al. Influence of newly synthesized cholesterol on bile acid synthesis during chronic inhibition of bile acid absorption. Hepatology 2003;38:939-46.

13 Heiss G, Tamir I, Davis CE, Tyroler HA, Rifkind BM, Schonfeld G et al. Lipoprotein-cholesterol distributions in selected North American populations: the Lipid Research Clinics Program Prevalence Study. Circulation 1980;61:30215.

14 Friedman GD, Kannel WB, Dawber TR. The epidemiology of gallbladder disease: observations in the Framingham Study. F Chronic Dis 1966;19:273-92.

15 Attili AF, Carulli N, Roda E, Barbara L, Capocaccia L, Menotti A et al. Epidemiology of gallstone disease in Italy: prevalence data of the Multicenter Italian Study on Cholelithiasis (M.I.COL.). Am F Epidemiol 1995;141:158-65.

16 Einarsson K, Nilsell K, Leijd B, Angelin B. Influence of age on secretion of cholesterol and synthesis of bile acids by the liver. N Engl f Med 1985;313:277-82.

17 Bertolotti M, Abate N, Bertolotti S, Loria P, Concari M, Messora R et al. Effect of aging on cholesterol $7 \alpha$-hydroxylation in humans. F Lipid Res 1993;34:1001-7.

18 Bertolotti M, Gabbi C, Anzivino C, Mitro N, Godio C, De Fabiani $\mathrm{E}$ et al. Decreased hepatic expression of PPAR- $\gamma$ coactivator-1 in cholesterol cholelithiasis. Eur $\mathcal{F}$ Clin Invest 2006;36:170-5.

19 De Fabiani E, Mitro N, Gilardi F, Caruso D, Galli G, Crestani M. Coordinated control of cholesterol catabolism to bile acids and of gluconeogenesis via a novel mechanism of transcription regulation linked to the fasted-to-fed cycle. $\mathcal{F}$ Biol Chem 2003;278:39124-32.

20 Axelson M, Björkhem I, Reihnér E, Einarsson K. The plasma level of 7 alpha-hydroxy-4-cholesten-3-one reflects the activity of hepatic cholesterol 7 alpha-hydroxylase in man. FEBS Lett 1991;284:216-8.

21 Rudling M, Angelin B, Ståhle L, Reihnér E, Sahlin S, Olivecrona $\mathrm{H}$ et al. Regulation of hepatic low-density lipoprotein receptor, 3-hydroxy-3-methylglutaryl Coenzyme A reductase, and cholesterol $7 \alpha$-hydroxylase mRNAs in human liver. F Clin Endocrinol Metab 2002;87:4307-13.

22 Abrahamsson A, Gustafsson U, Ellis E, Nilsson L-M, Sahlin $\mathrm{S}$, Björkhem I et al. Feedback regulation of bile acid synthesis in human liver: importance of $\mathrm{HNF}-4 \alpha$ for regulation of CYP7A1. Biochem Biophys Res Comm 2005;330:395-9.

23 Honda A, Salen G, Matsuzaki Y, Batta AK, Xu G, Hirayama $\mathrm{T}$ et al. Disrupted coordinate regulation of farnesoid $\mathrm{X}$ receptor target genes in a patient with cerebrotendineous xanthomatosis. f Lipid Res 2005;46:287-96. 
24 Crestani M, Sadeghpour A, Stroup D, Galli G, Chiang JYL. Transcriptional activation of the cholesterol $7 \alpha$-hydroxylase gene (CYP7A) by nuclear hormone receptors. $f$ Lipid Res 1998;39:2192-200.

25 Stroup D, Chiang JYL. HNF4 and COUP-TFII interact to modulate transcription of the cholesterol $7 \alpha$-hydroxylase gene (CYP7A1). F Lipid Res 2000;41:1-11.

26 Inoue Y, Yu A-M, Yim SH, Ma X, Krausz KW, Inoue J et al. Regulation of bile acid biosynthesis by hepatocyte nuclear factor

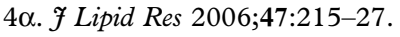

27 Paré J-F, Roy S, Galarneau L, Bélanger L. The mouse fetoprotein transcription factor (FTF) gene promoter is regulated by three GATA elements with tandem $\mathrm{E}$ box and $\mathrm{Nkx}$ motifs, and FTF in turn activates the $H n f 3 \beta, H n f 4 \alpha$, and $H n f 1 \alpha$ gene promoters. F Biol Chem 2001;276:13136-44.

28 Kerr TA, Saeki S, Schneider M, Schaefer K, Berdy S, Redder $\mathrm{T}$ et al. Loss of nuclear receptor SHP impairs but does not eliminate negative feedback regulation of bile acid synthesis. Dev Cell 2002;2:713-20.

29 Wang L, Le YK, Bundman D, Han Y, Thevananther S, Kim $\mathrm{CS}$ et al. Redundant pathways for negative feedback regulation of bile acid production. Dev Cell 2002;2:721-31.

30 Miyake JH, Wang SL, Davis RA. Bile acid induction of cytokine expression by macrophages correlates with repression of hepatic cholesterol 7 $\alpha$-hydroxylase. F Biol Chem 2000;275:21805-8.

31 De Fabiani E, Mitro N, Anzulovich AC, Pinelli A, Galli G, Crestani $M$. The negative effects of bile acids and tumor necrosis factor $\alpha$ on the transcription of the cholesterol $7 \alpha$-hydroxylase gene (CYP7A1) converge to hepatocyte nuclear factor-4. A novel mechanism of feedback regulation of bile acid synthesis mediated by nuclear receptors. $\mathcal{F}$ Biol Chem 2001;276:30708-16.

32 Marchesini G, Bua V, Brunori A, Bianchi G, Pisi P, Fabbri A et al. Galactose elimination capacity and liver volume in aging man. Hepatology 1988;8:1079-83.

33 Ceda GP, Dall'Aglio E, Magnacavallo A, Vargas N, Fontana $\mathrm{V}$, Maggio $\mathrm{M}$ et al. The insulin-like growth factor axis and plasma lipid levels in the elderly. F Clin Endocrinol Metab 1998: 83;499-502.

34 Lahuna O, Fernandez L, Karlsson H, Maiter D, Lemaigre FP, Rousseau GG et al. Expression of hepatocyte nuclear factor 6 in rat liver is sex-dependent and regulated by growth hormone. Proc Natl Acad Sci USA 1997;94:12309-13.

35 Lahuna O, Rastegar M, Maiter D, Thissen JP, Lemaigre FP,
Rousseau GG. Involvement of STAT5 (signal transducer and activator of transcription 5) and HNF-4 (hepatocyte nuclear factor 4) in the transcriptional control of the hnf6 gene by growth hormone. Mol Endocrinol 2000;14:285-94.

36 Elaswarapu S, Jiang H. Growth hormone regulates the expression of hepatocyte nuclear factor-3 gamma and other liver-enriched transcription factors in the bovine liver. f Endocrinol 2005;184:95-105.

37 Schrem H, Klempnauer J, Borlak J. Liver-enriched transcription factors in liver function and development. Part I: the hepatocyte nuclear factor network and liver-specific gene expression. Pharmacol Rev 2002;54:129-58.

38 Meton I, Boot EP, Sussenbach JS, Steenbergh PH. Growth hormone induces insulin-like growth factor-I gene transcription by a synergistic action of STAT5 and HNF-1alpha. FEBS Lett 1999;444:155-9.

39 Yang Q, Yamagata K, Fukui K, Cao Y, Nammo T, Iwahashi $\mathrm{H}$ et al. Hepatocyte nuclear factor-1 alpha modulates pancreatic beta-cell growth by regulating the expression of insulin-like growth factor-1 in INS-1 cells. Diabetes 2002;51:1785-92.

40 Rudling M, Parini P, Angelin B. Growth hormone and bile acid synthesis. Key role for the activity of hepatic microsomal cholesterol 7 alpha-hydroxylase in the rat. $\mathcal{F}$ Clin Invest 1997;99:2239-45.

41 Matasconi M, Parini P, Angelin B, Rudling M. Pituitary control of cholesterol metabolism in normal and LDL receptor knock-out mice: effects of hypophysectomy and growth hormone treatment. Biochim Biophys Acta 2005;1736: 221-7.

42 Heubi JE, Burstein S, Sperling MA, Gregg D, Subbiah MTR. Matthews DE. The role of human growth hormone in the regulation of cholesterol and bile acid metabolism. 7 Clin Endocrinol Metab 1983;57:885-91.

43 Lind S, Rudling M, Ericsson S, Olivecrona H, Eriksson M, Borgstrom B et al. Growth hormone induces low-density lipoprotein clearance but not bile acid synthesis in humans. Arterioscler Thromb Vasc Biol 2004;24:349-56.

44 Rudling M, Olivecrona H, Eggertsen G, Angelin B. Regulation of rat hepatic low density lipoprotein receptors. In vivo stimulation by growth hormone is not mediated by insulin-like growth factor I. F Clin Invest 1996;97:292-9.

45 Laron Z, Wang XL, Klinger B, Silbergeld A, Wilcken DE. Growth hormone increases and insulin-like growth factor-I decreases circulating lipoprotein (a). Eur F Endocrinol 1997;136:377-81. 